\title{
Tight glycaemic control in acute exacerbations of COPD
}

\section{$S$ J Finney, T W Evans}

\section{A new standard of care?}

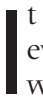
is now clear that hyperglycaemia of even short duration can be associated with adverse outcome in the acutely ill. Thus, the hyperglycaemic state has been associated with increased mortality in patients undergoing cardiothoracic surgery or suffering acute myocardial infarction, in victims of major trauma and those sustaining brain injury, and in association with community acquired pneumonia. ${ }^{1-5}$ In this issue of Thorax Baker and colleagues extend this list, having performed a retrospective analysis of outcome in patients admitted to hospital with an acute exacerbation of chronic obstructive pulmonary disease (COPD). ${ }^{6}$ Multivariate analysis revealed that hyperglycaemia held more adverse prognostic significance even than spirometry. Not surprisingly, the authors propound the hypothesis that rigorous glycaemic control should improve mortality and/or reduce the length of hospital stay in this patient population which is so commonly encountered during the acute general medical take. To this end, they propose that a randomised trial of insulin therapy should be undertaken.

How robust are the data presented in this potentially important study? Although the authors are commendably open about the limitations of their study, these may be significant. Firstly, their (retrospective) identification of patients relied entirely on clinical coding, audits of which have suggested levels of accuracy as low as $60 \% .^{7}$ It is therefore unlikely that the study population was both complete and homogeneous. Indeed, the microbiological data presented suggest that a degree of overlap with patients suffering from community acquired pneumonia is possible, in whom hyperglycaemia is known to be associated with a poor outcome. $^{5}$ Secondly, some measurements of blood glucose levels were made after hospital admission, during which the potentially significant confounding effects of therapeutic corticosteroids on glycaemic control were not quantified. Thirdly, single measurements of maximal blood glucose values were used in the analysis, which do not reflect the dynamic nature of levels encountered in acutely ill patients. Finney et $a l^{8}$ have shown that patients who spent the least time within the highest of several glycaemic bands $(>8.0 \mathrm{mmol} / \mathrm{l})$ were less likely to die than those who spent most time there. Detailed analysis of this kind is needed to facilitate precise quantification of dysfunctional glycaemic control. Finally, no data were presented that permit the assessment of severity of illness in this patient population, such as arterial $\mathrm{pH}$. Not only does this remove the potential benefit of making comparisons with previously published work in patients with COPD, ${ }^{9}$ but it also renders impossible any attempt to establish whether hyperglycaemia was simply a reflection of illness severity and not therefore specific to this patient population.

Are the results obtained by Baker and colleagues rational and explicable in scientific terms? While a rigorous approach to glycaemic control has been shown to confer benefit following cardiothoracic surgery ${ }^{4}$ and in patients suffering acute myocardial infarction, ${ }^{10}$ it is possible that these results are due to the administration of exogenous insulin. Insulin is known to have both antiinflammatory ${ }^{11}$ and anabolic properties, ${ }^{12}$ and also promotes the utilisation of glucose as a metabolic fuel which generates more molecules of ATP per molecule of oxygen than free fatty acids with obvious potential benefits for ischaemic tissue. However, following cardiothoracic surgery the dose of insulin administered appears to be less significant in determining outcome than the quality of blood glucose (or surrogate variable) control. ${ }^{8}{ }^{13}$ Moreover, glucose toxicity is suggested by postmortem studies of surgical patients in whom mitochondrial damage was limited to tissues characterised by the expression of glucose transporter (GLUT)-1 and GLUT-3, but not GLUT$4 .{ }^{14}$ GLUT- 1 and GLUT-3 are cell membrane transport proteins that allow equilibration of intracellular and extracellular glucose independently of insulin. Furthermore, hyperglycaemia causes many potentially damaging events such as the production of reactive oxygen species, ${ }^{15}$ glycosylation of proteins, impairment of leucocyte function, and activation of pro-inflammatory genes through the transcription factors $\mathrm{NF}-\kappa \mathrm{B}$ and AP-1. ${ }^{11}$ Alternatively, high plasma glucose levels may be a surrogate marker for deranged lipid metabolism. Insulin therapy appears to normalise lipid profiles with potentially beneficial consequences for membrane function and endotoxin scavenging. ${ }^{14}$ Finally, hyperglycaemia is associated with raised glucose levels both in tissues and bronchial aspirates, thereby potentially increasing the proliferation of pathogenic organisms, ${ }^{16}$ a positive finding of the present study. Since many of these theories are predicated upon the hypothesis that hyperglycaemia perpetuates inflammation either directly or through poor bacterial clearance/bacterial proliferation, quantification of the inflammatory response might provide a mechanistic insight in any subsequent study.

Should the results of this study change our clinical practice? The authors rightly emphasise that their investigation does not prove that administration of insulin is clinically beneficial. Furthermore, we could identify only one published interventional study that includes patients with respiratory failure. This historical, cohort based investigation found a reduction in mortality when insulin was administered to a mixed population of critically ill patients, ${ }^{17}$ only $12 \%$ of whom had a primary respiratory diagnosis. Many were mechanically ventilated. The insulin regimen applied was aimed at achieving blood glucose levels of $<7.8 \mathrm{mmol} / \mathrm{l}$, less rigorous than the targets of interventional studies performed in other populations.

Nevertheless, while there are limited data justifying tight glycaemic control in acutely ill medical patients, there are clearly no data or any scientific or clinical rationale to justify the maintenance of high blood glucose levels. On balance, it would appear that-based on only moderate evidence ${ }^{17}$ - aiming for a blood glucose level of $<8 \mathrm{mmol} / \mathrm{l}$ is reasonable in the acutely ill, even in those who are not known diabetics. Such uncertainty highlights the need for a trial of insulin therapy in patients with acute exacerbations of COPD, as Baker et al acknowledge. The logistic demands of tight glucose control should not, however, be underestimated. In a major randomised study of insulin therapy performed in the intensive care setting where staffing tends to be generous and monitoring apparatus readily available, blood sampling was recommended every $1-2$ hours initially. 
Ward based patients may have even more variable glucose levels due to the intermittent nature of their caloric intake, in contrast to the continuous feeding that occurs commonly in critical care. The compounding effects of glucocorticoid treatment, frequently used in patients with COPD, have already been highlighted. Insulin infusions carry a risk of inadvertent hypoglycaemia which increases as blood glucose targets become more stringent. Indeed, in a major study of insulin therapy which aimed for blood glucose levels between 4.4 and $6.0 \mathrm{mmol} / \mathrm{l}$, a $4.2 \%$ increase in the incidence of blood glucose levels of $<2.2 \mathrm{mmol} / \mathrm{l}$ was identified, although these episodes apparently had no adverse sequelae. ${ }^{4}$ Finally, the implications for nursing workload are considerable; the development of computerised infusion control systems may help.

If the benefits of tight glycaemic control on mortality in patients with acute exacerbations of COPD are proved, the potential impact on the health care of patients with such a common disease is enormous. It will be revealing if the outcome is significantly influenced by what many would consider to be routine medical care that should be undertaken in all patients.

Thorax 2006;61:275-276.

doi: $10.1136 /$ thx.2005.053546

\section{Authors' affiliations}

S J Finney, T W Evans, Adult Intensive Care Unit, Royal Brompton Hospital, London SW3 6LY, UK

Correspondence to: Professor T W Evans, Adult Intensive Care Unit, Royal Brompton Hospital, Sydney Street, London SW3 6LY, UK; t.evans@ rbht.nhs.uk

Competing interests: none.

\section{REFERENCES}

1 Modan B, Schor S, Shani M. Acute myocardial infarction. Prognostic value of white blood cell count and blood glucose level. JAMA 1975:233:266-7.

2 Capes SE, Hunt D, Malmberg K, et al. Stress hyperglycemia and prognosis of stroke in nondiabetic and diabetic patients: a systematic overview. Stroke 2001;32:2426-32

3 Yendamuri S, Fulda GJ, Tinkoff GH. Admission hyperglycemia as a prognostic indicator in trauma. J Trauma 2003;55:33-8.

4 Van den Berghe G, Wouters P, Weekers F, et al Intensive insulin therapy in the critically ill patients. N Engl J Med 2001;345:1359-67.

5 McAlister FA, Majumdar SR, Blitz S, et al. The relation between hyperglycemia and outcomes in 2,471 patients admitted to the hospital with community-acquired pneumonia. Diabetes Care 2005;28:810-5.

6 Baker EH, Janaway $\mathrm{CH}$, Philips BJ, et al. Hyperglycaemia is associated with poor outcomes in people admitted to hospital with acute exacerbations of chronic obstructive pulmonary disease. Thorax 2006;61:284-9.

7 NHS Connecting for Health. Clinical coding sample audits, 2006. Available at http://www.connectingforhealth.nhs.uk/ clinicalcoding/samples_clinical (accessed 7 January 2006).

8 Finney SJ, Zekveld C, Elia A, et al. Glucose control and mortality in critically ill patients. JAMA 2003;290:2041-7.

9 Plant PK, Owen JL, Elliott MW. Non-invasive ventilation in acute exacerbations of chronic obstructive pulmonary disease: long term survival and predictors of in-hospital outcome. Thorax 2001;56:708-12

10 Malmberg K, Ryden L, Efendic S, et al. Randomized trial of insulin-glucose infusion followed by subcutaneous insulin treatment in diabetic patients with acute myocardial infarction (DIGAMI study): effects on mortality at 1 year. $J$ Am Coll Cardio 1995:26:57-65.

11 Dandona P, Mohanty P, Chaudhuri A, et al Insulin infusion in acute illness. J Clin Invest 2005; 115:2069-72.

12 Mesotten D, Wouters PJ, Peeters RP, et al. Regulation of the somatotropic axis by intensive insulin therapy during protracted critical illness. J Clin Endocrinol Metab 2004;89:3105-13.

13 Van den Berghe G, Wouters PJ, Bouillon R, et al Outcome benefit of intensive insulin therapy in the critically ill: insulin dose versus glycemic control. Crit Care Med 2003;31:359-66.

14 Mesotten D, Swinnen JV, Vanderhoydonc F, et al. Contribution of circulating lipids to the improved outcome of critical illness by glycemic control with intensive insulin therapy. $J$ Clin Endocrinol Metab 2004;89:219-26.

15 Mohanty P, Hamouda W, Garg R, et al. Glucose challenge stimulates reactive oxygen species (ROS) generation by leucocytes. J Clin Endocrino Metab 2000:85:2970-3.

16 Philips BJ, Redman J, Brennan A, et al. Glucose in bronchial aspirates increases the risk of respiratory MRSA in intubated patients. Thorax 2005:60:761-4.

17 Krinsley JS. Effect of an intensive glucose management protocol on the mortality of critically ill adult patients. Mayo Clin Proc 2004;79:992-1000. little doubt that the prevalence of asthma was underestimated on both sides of the Atlantic

In the 1950s several papers on the epidemiology of childhood asthma appeared from Scandinavia, reporting prevalences of $0.6-1.4 \% .{ }^{8-11}$ These studies relied on identifying cases that were known to school doctors, nurses or other professional personnel, and the prevalence data are likely to have been underestimates, partly because of the method of ascertainment and partly because of the widespread diagnosis of bronchitis. $^{8}$

By 1967 the prevalence of asthma in children on the Isle of Wight was reported to be $2.3 \%{ }^{12}$ and in Aberdeen in 1969 the figure was $4.8 \%{ }^{13}$ a figure that excluded $6.7 \%$ of children who wheezed only in the presence of infection.

Taking these figures at face value, it appeared that the prevalence of asthma had climbed steadily from $0.53 \%{ }^{4}$ to $4.8 \%{ }^{13}$ over a period of 40 years. Thus, although these data must be viewed with extreme caution, there is nothing new about the idea that childhood asthma is becoming more prevalent. 